\title{
MORFOLOGIA DE AGREGADOS DE LATOSSOLOS BRUNO E VERMELHO DO ESTADO DO PARANÁ, AVALIADA POR IMAGENS OBTIDAS EM SCANNER ${ }^{(1)}$
}

\author{
Vander de Freitas Melo ${ }^{(2)}$, Rodrigo de Moura ${ }^{(3)}$, Fernando Henrique \\ Toledo $^{(3)}$, Valmiqui Costa Lima ${ }^{(4)}$ \& André Ademir Ghidin ${ }^{(5)}$
}

\begin{abstract}
RESUMO
A forma e o tamanho das estruturas definem a maioria das características dos solos, principalmente a porosidade total e a distribuição dessa porosidade em macro e microporos. Objetivou-se neste trabalho o estudo da morfologia de diferentes classes de tamanho de agregados de duas toposseqüências de Latossolos (Latossolo Bruno distrófico húmico - LBd e Latossolo Vermelho distroférrico húmico - LVdf), ambos sob condições naturais e originados de rochas basálticas no Paraná, por meio de análise de imagens. Foram coletadas amostras indeformadas de dois horizontes (Bw1 e Bw2) nas toposseqüências do LBd (quatro perfis) e do LVdf (três perfis). Após secagem, as amostras foram separadas em seis classes de tamanho de agregados (2-4 mm;1-2 mm; 0,5-1 mm; 0,25-0,5 mm; 0,105-0,25 mm; e $<0,105 \mathrm{~mm}$ ), determinando-se a distribuição percentual e o diâmetro médio geométrico (DMG). As imagens dos agregados das quatro maiores classes foram obtidas com scanner e processadas pelo programa de computador UTHSCSA Image Tool. Os agregados do LBd e do LVdf foram predominantemente poliedrais e rugosos, o que deve contribuir para aumentar a superfície externa destes. Os maiores valores de DMG, área e perímetro dos agregados foram verificados para o LBd, sobretudo para o horizonte mais profundo (Bw2). O grau de arredondamento aumentou com a diminuição da classe de tamanho dos agregados para ambos os solos, ou seja, agregados menores tendem a ser mais esféricos e menos rugosos. A
\end{abstract}

\footnotetext{
(1) Recebido para publicação em outubro de 2006 e aprovado em setembro de 2007.

(2) Professor do Departamento de Solos e Engenharia Agrícola, Universidade Federal do Paraná - UFPR. Rua dos Funcionários 1540, CEP 80035-050 Curitiba (PR). Bolsista CNPq. E-mail: vanderfm@ufpr.br

(3) Acadêmico do Curso de Agronomia, UFPR. Bolsista PIBIC/CNPq. E-mails: rodemoura@ufpr.br; zumbi@ufpr.br

(4) Professor do Departamento de Solos e Engenharia Agrícola, UFPR. E-mail: valmiqui@ufpr.br

(5) Professor do Curso de Gestão Ambiental, Faculdade Palas Atena - FPA. CEP 85560-000 Chopinzinho (PR). E-mail: ghidin@chnet.com.br
} 


\begin{abstract}
qualidade da fração argila teve efeito não apenas no tamanho dos agregados, mas também na morfologia externa destes. Para algumas classes de tamanho de agregados dos horizontes do LBd e do LVdf, o aumento no DMG e na área, o crescimento preferencial em um eixo (alongamento) e a redução da rugosidade externa dos agregados foram favorecidos pelo maior teor de caulinita na fração argila. Efeito oposto foi verificado para os óxidos de Fe e Al.
\end{abstract}

Termos de indexação: alongamento e rugosidade do agregado, caulinita, óxidos de Fe e Al.

\title{
SUMMARY: MORPHOLOGY OF SOIL STRUCTURE OF THE RED-YELLOW AND DUSKY RED LATOSOLS OF PARANÁ STATE, BRAZIL, BY SCANNER IMAGE ANALYSES
}

\begin{abstract}
The shape and size of aggregates define most soil characteristics, mainly the total porosity and macro and micropore distribution. This study aimed to investigate the morphology of soil aggregates of different size classes of a Red-Yellow (LBd) and a Dusky Red Latosol (LVdf) located in two respective natural toposequences, in Paraná State, Brazil, using scanner images. Undisturbed soil samples of the BW1 and Bw2 horizons were collected in four $L B d$ profiles and three profiles of the $L V d f$ toposequence. After drying, the aggregates were separated into six size-classes (2-4 $\mathrm{mm} ; 1-2 \mathrm{~mm} ; 0.5-1 \mathrm{~mm}$; $0.25-0.5 \mathrm{~mm} ; 0.105-0.25 \mathrm{~mm} ;<0.105 \mathrm{~mm})$, to determine the percentage mass distribution and geometric mean diameter (GMD). Aggregate images of the four coarsest size-classes were scanned and processed by UTHSCSA Image Tool. The aggregate shape of both soils was predominantly polyedric, with high roughness, which supposedly increases the external surface area of aggregates. A higher GMD, aggregate area and perimeter were verified in $L B d$ than in the LVdf samples, especially in the Bw2 horizon. The aggregate roundness increased with the decrease in aggregate size, i.e., smaller aggregates seemed to be more spherical and less rough. The clay mineralogy was related with both size and surface morphology of the aggregates. In some size classes of the $L B d$ and LVdf horizons, an increased GMD and area, the preferential growth in one axe (lengthiness) and the external roughness reduction of the structures were favored by the kaolinite content in the clay fraction. The opposite effect was verified for $\mathrm{Fe}$ and $\mathrm{Al}$ oxides.
\end{abstract}

Index terms: aggregate elongation and roughness, $\mathrm{Fe}$ and $\mathrm{Al}$ oxides, kaolinite.

\section{INTRODUÇÃO}

A estrutura é um fator-chave dos solos, em suas habilidades de suportar plantas e animais e moderar a qualidade do ambiente, pois influencia diretamente o movimento e retenção de água, erosão, encrostamento superficial, ciclagem de nutrientes, penetração de raízes, poluição da água superficial e subterrânea e trocas gasosas com a atmosfera. Os agregados ocorrem em várias formas e tamanhos e são, freqüentemente, agrupados em macroagregados $(>250 \mu \mathrm{m})$ e microagregados $(<250 \mu \mathrm{m})$ (Edwards \& Bremmer, 1967). O estudo da morfologia dos agregados reveste-se de grande interesse agronômico e ambiental - por exemplo, agregados esferoidais, principalmente aqueles de menor tamanho, de grande ocorrência nos Latossolos, deixam grande volume de macroporos no solo (Ghidin et al., 2006b), o que facilita a infiltração de água e o crescimento das raízes das plantas.
Portanto, técnicas que permitem o estudo preciso da forma e tamanho dos agregados - mais especificamente, o grau de arredondamento ou de rugosidade da superfície externa - são importantes como ferramenta para previsão de eventos práticos na utilização dos solos. Olszevski et al. (2004) utilizaram scanner para aquisição de imagens e adaptaram o programa de computador UTHSCSA Image Tool (Wilcox et al., 1997) para descrever com detalhe os agregados de diferentes tamanhos de um Latossolo Vermelho distrófico de Sete Lagoas (MG), submetido a diferentes tipos de manejo. Como resultado prático, os autores não observaram efeitos morfológicos expressivos nos agregados do solo, mesmo após três anos consecutivos de uso.

Os agregados são unidades secundárias formadas pela combinação de partículas minerais com substâncias orgânicas e inorgânicas, em decorrência das cargas elétricas superficiais das partículas coloidais. A dinâmica complexa da floculação das 
partículas sólidas e agregação do solo é resultado da interação de vários fatores, incluindo ambientais, manejo do solo, influência da planta e propriedades do solo, como textura, composição mineral, teor de carbono orgânico, processos pedogenéticos, atividade microbiana, íons trocáveis, reserva de nutrientes e umidade (Singer et al., 1992; Denef et al., 2002; Six et al., 2004).

A forma dos minerais da fração argila é considerada um importante fator na definição do tamanho e da forma dos agregados. A caulinita, gibbsita, goethita e hematita são os principais minerais da fração argila dos Latossolos brasileiros, apresentando diferentes concentrações e características físico-químicas (Kämpf et al., 1988a,b; Singh \& Gilkes, 1992; Melo et al., 2001a,b). A participação quantitativa desses minerais nas características físicas dos solos foi discutida em vários trabalhos (Schwertmann \& Kämpf, 1985; Pinheiro-Dick \& Schwertmann, 1995; Ferreira et al., 1999a). Resende (1985) e Resende et al. (1992, 1997) atribuíram, principalmente, à hematita, gibbsita $\mathrm{e}$ goethita o efeito desorganizador dos minerais filossilicatos na fração argila, destacando-se a caulinita. Assim, o maior teor destes constituintes corresponde à maior grau de desorganização microscópica e, conseqüentemente, a uma estrutura mais próxima do tipo granular. Por outro lado, os autores também discutem o efeito da caulinita na agregação dos Latossolos, atribuindo ao arranjo face a face do mineral a estrutura predominantemente em blocos.

Avaliando apenas o efeito da espécie mineral da fração argila sobre as propriedades físicas dos Latossolos, Ferreira et al. (1999b) reportaram a maior participação dos óxidos de $\mathrm{Al}$ na definição da morfologia dos agregados dos Latossolos, em relação ao óxidos de Fe. Por outro lado, o trabalho de Pinheiro-Dick \& Schwertmann (1995) não conseguiu distinguir o efeito dessas duas classes de minerais, e a presença dos óxidos de $\mathrm{Fe}$ e $\mathrm{Al}$ resultou, indistintamente, na alta estabilidade dos agregados dos Oxissolos. Segundo esses autores, tanto as formas de Fe pobremente cristalinas quanto a goethita e hematita participaram efetivamente dos processos de agregação.

O objetivo deste trabalho foi estudar a morfologia de diferentes classes de tamanho de agregados dos horizontes Bw1 e Bw2 de perfis de Latossolos Bruno e Vermelho, por meio de análise de imagens obtidas em scanner, bem como correlacionar as características morfológicas de cada classe de tamanho com a mineralogia da fração argila da respectiva classe.

\section{MATERIAL E MÉTODOS}

As áreas estudadas pertencem aos municípios de Guarapuava e Cascavel (PR) (Terceiro Planalto Paranaense). Segundo Schneider (1970), em área próxima a Cascavel, a rocha é o basalto vacuolar, o qual apresenta coloração preta, brilho resinoso, com predomínio de plagioclásio, piroxênios, magnetita e presença de alguns secundários (cloritas esverdeadas e óxidos e hidróxidos de Fe). Em Guarapuava foi identificado o andesi-basalto pórfiro (rocha mais ácida), o qual apresenta coloração cinza-clara a cinza-escura, com predomínio de plagioclásio (andesina), piroxênio (hiperstênio e augita), opacos (magnetita) e quartzo.

Foram abertas quatro trincheiras em Guarapuava [(Latossolo Bruno distrófico húmico - LBd - Embrapa, (1999)] e três em Cascavel (Latossolo Vermelho distroférrico húmico - LVdf), coletando-se amostras indeformadas dos horizontes Bw1 e Bw2. Obteve-se a seguinte distribuição das trincheiras nos segmentos da toposseqüência (declividade média de $5 \%$ e comprimento médio de rampa de $400 \mathrm{~m}$ ): LBd-P1, terço superior da encosta (TSE); P2, terço médio/ superior da encosta (TMSE); P3, terço médio da encosta (TME); e P4, terço inferior da encosta; e LVdfP1, TSE; P2, TME; e P3, TIE. As características morfológicas dos perfis (P1 a P4 para o LBd e P1 a P3 para o LVdf) e as análises químicas das amostras deformadas dos horizontes (TFSA) podem ser obtidas em Ghidin et al. (2006a).

A toposseqüência em Guarapuava localizou-se no Parque Ambiental das Araucárias, situado na latitude de $25^{\circ} 21^{\prime} 50$ " sul e longitude de $51^{\circ} 28^{\prime} 33^{\prime}$ oeste, com altitude de $1.068 \mathrm{~m}$. O clima, segundo a classificação de Köppen, é Cfb, com precipitação pluvial de 1.600 a $1.800 \mathrm{~mm}$ (IAPAR, 2000). A toposseqüência em Cascavel, também em área de preservação ambiental, localizou-se no Parque Ambiental de Cascavel, situado na latitude de $24^{\circ} 27^{\prime} 21^{\prime \prime}$ sul e longitude de $53^{\circ} 27^{\prime} 19$ " oeste, com altitude de $781 \mathrm{~m}$. O clima é o Cfa, e a média da precipitação pluvial é de 1.800 a 2.000 mm (IAPAR, 2000).

Após secagem ao ar, foram pesados cerca de $500 \mathrm{~g}$ de amostras (torrões) dos horizontes Bw1 e Bw2 dos perfis P1 a P4 do LBd e dos perfis P1 a P3 do LVdf; em seguida, foram separadas seis classes de tamanhos de agregados $(4-2 ; 1-2 ; 0,5-1 ; 0,25-0,5 ; 0,105-0,25$; e $<0,105 \mathrm{~mm}$ ), utilizando-se um sistema de peneiras acopladas a um agitador orbital, com agitação por 5 min (estabilidade de agregados via seca - Embrapa (1997). A velocidade de trabalho do aparelho foi na escala 7, quando este oferece opções na faixa de 0 a 10. A quantidade de amostra (torrões) usada na separação das classes de agregados foi definida com base em testes prévios para distribuição adequada dos agregados na primeira peneira e para submeter as amostras às mesmas condições experimentais.

Os agregados retidos em cada peneira foram transferidos para placas de porcelana e determinaramse o peso do material seco e a percentagem de cada classe de agregados. Para expressar a distribuição dos agregados, utilizou-se o índice por tamanho (diâmetro médio geométrico - DMG), calculado pela seguinte fórmula (Kemper \& Rosenau, 1986): 


$$
\begin{gathered}
\mathrm{DMG}=10^{\mathrm{X}} \\
\mathrm{X}=[\Sigma(\mathrm{n} \log \mathrm{d}) / \Sigma \mathrm{n}]
\end{gathered}
$$

em que $\mathrm{n}=$ massa dos agregados retidos em determinada peneira (g); e d = diâmetro médio de determinada faixa de tamanho do agregado $(\mathrm{mm})$.

Realizou-se o estudo da forma e do tamanho dos agregados (Figura 1), após aquisição de imagens com o uso de scanner (HP 2400). Pequena quantidade de amostra das quatro maiores classes de agregados (2$4 ; 1-2 ; 0,5-1 ;$ e $0,25-0,5 \mathrm{~mm}$ ) foi espalhada sobre uma placa de vidro, não excedendo as dimensões de $20 \times 20 \mathrm{~cm}$, e os agregados foram separados manualmente, um a um, com auxílio de estilete e de lupa. A resolução utilizada foi de 600 dpi para todos os agregados analisados. A exclusão das duas menores classes no estudo morfológico foi devida à dificuldade operacional, falta de nitidez das imagens dos agregados menores e dificuldade de distinção entre agregados e poeira na placa de vidro.

As imagens foram processadas (exemplo apresentado na Figura 2) por meio do programa de computador denominado UTHSCSA Image tool

(a)
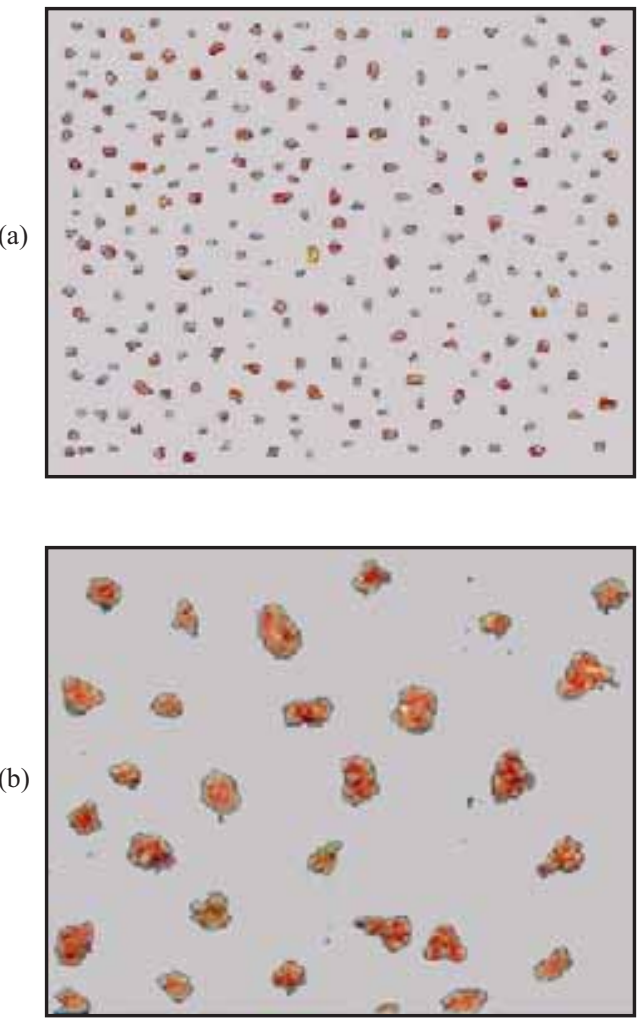

Figura 1. Imagem obtida no scanner dos agregados da classe de tamanho de 1 a 2 mm do horizonte Bw2 do perfil 3 do Latossolo Bruno. (a) imagem original; e (b) imagem ampliada (zoom), mostrando as diferentes morfologias dos agregados.
(Wilcox et al., 1997), adaptado para utilização em estudo de morfologia de agregados por Olszevski et al. (2004). O programa gera um número para cada agregado (Figura 2b), realizando o estudo morfológico individualizado. Ao final, em planilhas do tipo Excel, o programa calcula o somatório e os valores médios das variáveis estudadas. Para eliminar interferências, após identificação de partículas na imagem processada (Figura 2a) que não eram agregados (partículas de poeira que se desprenderam durante o espalhamento dos agregados sobre o scanner), mas que foram numeradas, a linha com os valores correspondentes a esses números (impurezas) foi diretamente eliminada na planilha de cálculo.

As variáveis analisadas nos agregados foram (Olszevski et al., 2004): área, perímetro, comprimento do maior eixo e do menor eixo, grau de arredondamento, alongamento, diâmetro de Feret e compacidade. Essas variáveis fornecem informações sobre o tamanho, a forma e a rugosidade dos agregados:

Área (Ar): corresponde ao número de pixels no polígono.

Perímetro (Pm): comprimento da projeção do limite exterior do agregado.

(a)

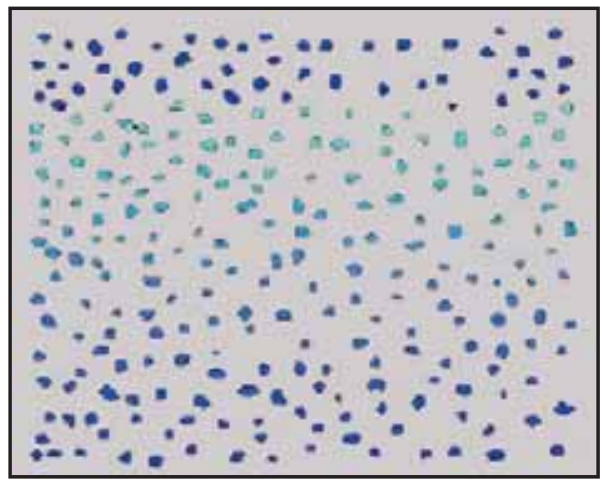

(b)

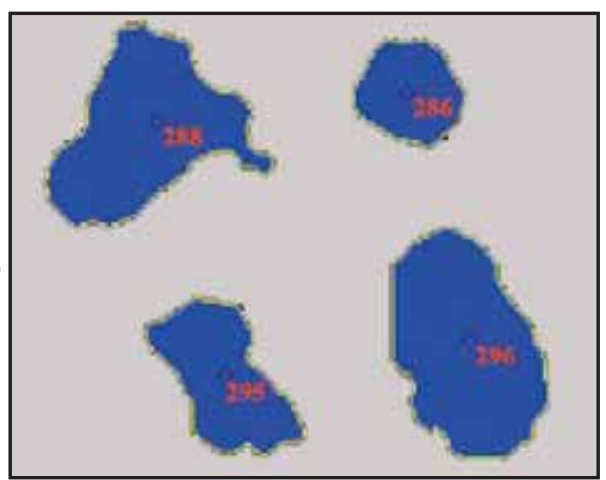

Figura 2. Imagem processada pelo programa UTHSCSA Image tool dos agregados da classe de tamanho de 1 a 2 mm do horizonte Bw2 do perfil 3 do Latossolo Bruno. (a) imagem original processada; e (b) imagem processada e ampliada (zoom), mostrando a numeração de cada agregado feita pelo programa. 
Comprimento do maior eixo (CME): comprimento de uma linha traçada perpendicularmente ao maior eixo do agregado.

Comprimento do menor eixo: comprimento de uma linha traçada perpendicularmente ao menor eixo do agregado.

Alongamento: relação entre o comprimento do menor eixo e o comprimento do maior eixo. O resultado é um valor entre 0 e 1 . Quando maior o valor, menor é a diferença entre os comprimentos dos eixos perpendiculares e menor o alongamento.

Arredondamento (Ard): medida dependente da rugosidade da superfície externa do agregado (perímetro - Pm). Fornecerá o resultado entre 0 e 1; quanto maior o valor, maior o grau de arredondamento.

$$
\operatorname{Ard}=(4 \pi \mathrm{Ar}) / \mathrm{Pm}^{2}
$$

Diâmetro de Feret (DF): diâmetro de um círculo com a mesma área do objeto.

$$
\mathrm{DM}=(4 \mathrm{Ar} / \mathrm{p})^{1 / 2}
$$

Compacidade $(\mathrm{Cmp})$ : fornece uma medida da circularidade do objeto, sendo dependente da medida do comprimento do maior eixo. Varia de 0 a 1 ; se for igual a 1 , o agregado é perfeitamente circular.

$$
\mathrm{Cmp}=(4 \mathrm{Ar} / \pi)^{1 / 2} / \mathrm{CME}
$$

Com o objetivo de verificar o efeito dos minerais sobre os aspectos morfológicos dos agregados dos horizontes Bw1 e Bw2 dos perfis do LBd e do LVdf, os dados mineralógicos da fração argila determinados por Melo et al. (2008) (Quadro 1) e os obtidos no presente estudo para os agregados da mesma classe de tamanho foram submetidos a análises estatísticas de correlação simples (Pearson), utilizando-se o programa SPSS for Windows 10.0. As correlações com a distribuição e o diâmetro médio geométrico foram feitas com os dados das seis classes de agregados $(2-4 ; 1-2$; $0,5-1 ; 0,25-0,5 ; 0,105-0,25 ;$ e $<0,105 \mathrm{~mm})$, e das características morfológicas (área, perímetro, arredondamento, diâmetro de Feret e compacidade), com apenas os dados das quatro maiores classes de agregados escaneadas.

\section{RESULTADOS E DISCUSSÃO}

\section{Distribuição dos agregados em classes de tamanho}

A maior proporção de agregados para o LVdf foi observada para a classe intermediária de tamanho
(0,25-0,5 mm) (Quadro 2). Verificou-se o mesmo comportamento para o perfil localizado no terço superior da encosta para o LBd, enquanto para os perfis 2, 3 e 4, principalmente para o horizonte Bw2, houve maior retenção de agregados na maior classe de tamanho (2-4 mm). De maneira análoga, os maiores valores de diâmetro médio geométrico dos agregados (DMG) foram obtidos para o horizonte $\mathrm{Bw} 2$ das posições mais baixas da toposseqüência do $\mathrm{LBd}$.

De acordo com os dados obtidos por Melo et al. (2008), verifica-se grande variação nos teores de caulinita, para um mesma classe de agregados, na toposseqüência do LBd e do LVdf (Quadro 1). Quanto maior o teor de caulinita na fração argila das maiores classes de agregados (2-4 e 1-2 mm), maior participação dessas classes nos horizontes do LBd $\left(\mathrm{r}=0,9^{*}\right.$ e $0,7^{\circ}$, respectivamente - Quadro 3), o que evidencia o efeito positivo da caulinita no tamanho dos agregados, em função do arranjo face a face desse mineral (Resende et al., 1997). O mesmo efeito pode ser observado na classe de $2-4 \mathrm{~mm}$ para o LVdf $\left(r=0,8^{\circ}\right)$. Por outro lado, os horizontes do LBd que apresentaram a maior percentagem de agregados de menor tamanho (classes menores que $1 \mathrm{~mm}$ ) também mostraram menor teor de caulinita na fração argila na mesma classe de agregados (coeficientes de correlação negativos e significativos).

O maior teor de goethita na fração argila dos agregados $<0,105 \mathrm{~mm}$ resultou na maior percentagem dessa classe de agregados nos horizontes do $\mathrm{LBd}(\mathrm{r}=$ $0,8^{*}$ - Quadro 3), que está de acordo com o trabalho de Resende et al. (1992), em que os maiores teores dos óxidos de $\mathrm{Fe}$ e $\mathrm{Al}$ favoreceram a redução do tamanho das estruturas do solo. O mesmo efeito, também esperado para hematita, não foi observado para o LVdf (solo com maior teor de hematita - Quadro 1), onde os maiores teores do mineral nos agregados menores que $0,5 \mathrm{~mm}$ favoreceram a redução da percentagem das menores classes de agregados (Quadro 3). Com relação à gibbsita, não se verificou comportamento consistente entre teor do mineral e distribuição das classes dos agregados (Quadro 3).

\section{Morfologia dos agregados}

Os dados da morfologia dos agregados por análise de imagens obtidas no scanner são apresentados por classe de tamanho (Quadros 4 a 7). Para o LBd a área média dos agregados do horizonte $\mathrm{Bw} 2$ das classes de tamanho de 2-4, 1-2 e 0,25-0,5 mm foi maior em relação à do horizonte Bw1 (Quadros 4, 5 e 7), confirmando os dados obtidos para o DMG para essas classes de agregados (Quadro 2). Na classe 0,5-1 mm não houve comportamento consistente para a área dos agregados entre os horizontes Bw1 e Bw2 (Quadro 6).

Quanto maior o teor de óxidos de $\mathrm{Fe}$ e $\mathrm{Al}$ cristalinos (gibbsita+goethita+hematita) na classe de 0,25-0,5 mm, menor a área média dessa classe de agregados nos horizontes do $\operatorname{LBd}\left(\mathrm{r}=-0,87^{* * *}-\right.$ Quadro 8$)$. Conforme 
Quadro 1. Composição mineralógica da fração argila das amostras das diferentes classes de agregados dos perfis do Latossolo Bruno (LBd) e Latossolo Vermelho (LVdf) ${ }^{(1)}$

\begin{tabular}{|c|c|c|c|c|c|c|c|}
\hline \multirow[t]{3}{*}{ Solo, perfil e horizonte } & \multirow[t]{3}{*}{ Classe } & Caulinita & Gibbsita & Goethita & Hematita & Amorfo & Óx. total \\
\hline & & \multicolumn{6}{|c|}{$\mathrm{g} \mathrm{kg}^{-1}$} \\
\hline & & \multicolumn{6}{|c|}{ Latossolo Bruno (LBd) } \\
\hline LBd P1 Bw1 & 1 & 423 & 311 & 103 & 69 & 44 & 483 \\
\hline LBd P1 Bw2 & 1 & 405 & 247 & 78 & 73 & 35 & 398 \\
\hline $\mathrm{LBd}$ P2 Bw1 & 1 & 425 & 296 & 121 & 42 & 19 & 459 \\
\hline $\mathrm{LBd}$ P2 Bw2 & 1 & 560 & 269 & 77 & 70 & 18 & 416 \\
\hline LBd P3 Bw1 & 1 & 435 & 317 & 98 & 70 & 44 & 485 \\
\hline LBd P3 Bw2 & 1 & 507 & 299 & 78 & 83 & 39 & 460 \\
\hline $\mathrm{LBd}$ P4 Bw 1 & 1 & 509 & 298 & 98 & 41 & 39 & 437 \\
\hline $\mathrm{LBd}$ P4 Bw2 & 1 & 557 & 204 & 100 & 21 & 18 & 325 \\
\hline $\mathrm{LBd} \mathrm{P} 1 \mathrm{Bw} 1$ & 2 & 408 & 307 & 100 & 58 & 55 & 465 \\
\hline $\mathrm{LBd}$ P1 Bw2 & 2 & 512 & 282 & 93 & 71 & 18 & 446 \\
\hline $\mathrm{LBd}$ P2 Bw1 & 2 & 519 & 330 & 138 & 33 & 25 & 501 \\
\hline LBd P2 Bw2 & 2 & 508 & 273 & 80 & 77 & 21 & 430 \\
\hline LBd P3 Bw1 & 2 & 410 & 321 & 125 & 46 & 39 & 492 \\
\hline $\mathrm{LBd}$ P3 Bw2 & 2 & 499 & 297 & 78 & 81 & 38 & 456 \\
\hline $\mathrm{LBd}$ P4 Bw1 & 2 & 538 & 309 & 102 & 46 & 51 & 457 \\
\hline $\mathrm{LBd}$ P4 Bw 2 & 2 & 543 & 194 & 109 & 22 & 42 & 325 \\
\hline $\mathrm{LBd}$ P1 Bw1 & 3 & 510 & 314 & 111 & 66 & 29 & 491 \\
\hline $\mathrm{LBd}$ P1 Bw2 & 3 & 499 & 295 & 84 & 86 & 30 & 465 \\
\hline $\mathrm{LBd}$ P2 Bw1 & 3 & 517 & 321 & 147 & 37 & 20 & 505 \\
\hline $\mathrm{LBd}$ P2 Bw2 & 3 & 482 & 276 & 86 & 64 & 22 & 426 \\
\hline LBd P3 Bw1 & 3 & 414 & 322 & 105 & 57 & 53 & 484 \\
\hline LBd P3 Bw2 & 3 & 536 & 296 & 80 & 82 & 18 & 458 \\
\hline $\mathrm{LBd}$ P4 Bw 1 & 3 & 597 & 305 & 97 & 52 & 43 & 454 \\
\hline $\mathrm{LBd} \mathrm{P} 4 \mathrm{Bw} 2$ & 3 & 572 & 203 & 97 & 29 & 38 & 329 \\
\hline $\mathrm{LBd}$ P1 Bw1 & 4 & 423 & 310 & 103 & 41 & 29 & 454 \\
\hline $\mathrm{LBd} \mathrm{P} 1 \mathrm{Bw} 2$ & 4 & 585 & 306 & 84 & 84 & 35 & 474 \\
\hline $\mathrm{LBd}$ P2 Bw1 & 4 & 442 & 312 & 134 & 43 & 25 & 489 \\
\hline LBd P2 Bw2 & 4 & 502 & 275 & 79 & 72 & 22 & 426 \\
\hline $\mathrm{LBd}$ P $3 \mathrm{Bw} 1$ & 4 & 457 & 320 & 95 & 57 & 49 & 472 \\
\hline LBd P3 Bw2 & 4 & 496 & 303 & 85 & 70 & 24 & 458 \\
\hline $\mathrm{LBd}$ P4 Bw1 & 4 & 571 & 318 & 0 & 108 & 47 & 426 \\
\hline $\mathrm{LBd} \mathrm{P} 4 \mathrm{Bw} 2$ & 4 & 567 & 201 & 106 & 28 & 24 & 335 \\
\hline $\mathrm{LBd}$ P1 Bw1 & 5 & 490 & 314 & 106 & 57 & 31 & 477 \\
\hline $\mathrm{LBd} \mathrm{P} 1 \mathrm{Bw} 2$ & 5 & 471 & 297 & 76 & 77 & 27 & 450 \\
\hline LBd P2 Bw1 & 5 & 475 & 312 & 158 & 31 & 26 & 501 \\
\hline $\mathrm{LBd}$ P2 Bw2 & 5 & 550 & 295 & 73 & 67 & 15 & 435 \\
\hline $\mathrm{LBd}$ P3 Bw 1 & 5 & 453 & 333 & 113 & 55 & 49 & 501 \\
\hline LBd P3 Bw2 & 5 & 535 & 299 & 99 & 70 & 24 & 468 \\
\hline $\mathrm{LBd} \mathrm{P} 4 \mathrm{Bw} 1$ & 5 & 502 & 294 & 93 & 45 & 44 & 432 \\
\hline $\mathrm{LBd}$ P4 Bw 2 & 5 & 628 & 217 & 98 & 17 & 34 & 332 \\
\hline $\mathrm{LBd}$ P1 Bw1 & 6 & 361 & 232 & 122 & 47 & 38 & 401 \\
\hline $\mathrm{LBd}$ P1 Bw2 & 6 & 489 & 300 & 75 & 71 & 25 & 446 \\
\hline $\mathrm{LBd}$ P2 Bw1 & 6 & 486 & 323 & 187 & 46 & 28 & 556 \\
\hline LBd P2 Bw2 & 6 & 560 & 295 & 64 & 75 & 27 & 434 \\
\hline LBd P3 Bw1 & 6 & 447 & 323 & 103 & 65 & 52 & 491 \\
\hline LBd P3 Bw2 & 6 & 522 & 308 & 74 & 83 & 23 & 465 \\
\hline $\mathrm{LBd} \mathrm{P} 4 \mathrm{Bw} 1$ & 6 & 659 & 329 & 89 & 43 & 43 & 461 \\
\hline $\mathrm{LBd}$ P4 Bw2 & 6 & 587 & 205 & 83 & 41 & 28 & 329 \\
\hline
\end{tabular}


Quadro 1. Continuação

\section{Solo, perfil e horizonte Classe Caulinita Gibbsita Goethita Hematita Amorfo Óx. total}

\begin{tabular}{|c|c|c|c|c|c|c|c|}
\hline \multirow[b]{2}{*}{ LVdf P1 Bw 1} & \multirow[b]{2}{*}{1} & \multicolumn{6}{|c|}{ Latossolo Vermelho (LVdf) } \\
\hline & & 388 & 350 & 38 & 166 & 38 & 554 \\
\hline LVdf P1 Bw2 & 1 & 393 & 371 & 34 & 192 & 31 & 597 \\
\hline LVdf P2 Bw1 & 1 & 412 & 377 & 32 & 240 & 16 & 649 \\
\hline LVdf P2 Bw2 & 1 & 426 & 367 & 25 & 220 & 32 & 612 \\
\hline LVdf P3 Bw1 & 1 & 411 & 308 & 53 & 199 & 29 & 560 \\
\hline LVdf P3 Bw2 & 1 & 328 & 346 & 44 & 189 & 24 & 579 \\
\hline LVdf P1 Bw1 & 2 & 375 & 351 & 58 & 200 & 37 & 609 \\
\hline LVdf P1 Bw2 & 2 & 421 & 373 & 2 & 222 & 32 & 597 \\
\hline LVdf P2 Bw 1 & 2 & 375 & 381 & 39 & 197 & 19 & 617 \\
\hline LVdf P2 Bw2 & 2 & 429 & 367 & 43 & 228 & 16 & 638 \\
\hline LVdf P3 Bw1 & 2 & 367 & 302 & 56 & 180 & 22 & 538 \\
\hline LVdf P3 Bw2 & 2 & 348 & 351 & 50 & 198 & 26 & 599 \\
\hline LVdf P1 Bw1 & 3 & 375 & 352 & 64 & 179 & 40 & 595 \\
\hline LVdf P1 Bw2 & 3 & 403 & 372 & 23 & 197 & 27 & 592 \\
\hline LVdf P2 Bw1 & 3 & 364 & 360 & 15 & 204 & 18 & 579 \\
\hline LVdf P2 Bw2 & 3 & 414 & 372 & 37 & 310 & 22 & 719 \\
\hline LVdf P3 Bw1 & 3 & 416 & 314 & 48 & 188 & 26 & 550 \\
\hline LVdf P3 Bw2 & 3 & 328 & 341 & 41 & 192 & 33 & 574 \\
\hline LVdf P1 Bw1 & 4 & 377 & 353 & 40 & 222 & 36 & 615 \\
\hline LVdf P1 Bw2 & 4 & 376 & 366 & 18 & 206 & 32 & 590 \\
\hline LVdf P2 Bw 1 & 4 & 383 & 353 & 35 & 186 & 27 & 574 \\
\hline LVdf P2 Bw2 & 4 & 401 & 363 & 33 & 228 & 19 & 624 \\
\hline LVdf P3 Bw1 & 4 & 357 & 298 & 60 & 191 & 26 & 549 \\
\hline LVdf P3 Bw2 & 4 & 326 & 346 & 44 & 176 & 33 & 566 \\
\hline LVdf P1 Bw1 & 5 & 362 & 344 & 56 & 197 & 31 & 597 \\
\hline LVdf P1 Bw 2 & 5 & 410 & 374 & 32 & 166 & 35 & 572 \\
\hline LVdf P2 Bw1 & 5 & 361 & 366 & 34 & 207 & 26 & 607 \\
\hline LVdf P2 Bw2 & 5 & 400 & 346 & 31 & 201 & 33 & 578 \\
\hline LVdf P3 Bw1 & 5 & 399 & 309 & 60 & 205 & 22 & 574 \\
\hline LVdf P3 Bw2 & 5 & 313 & 341 & 36 & 182 & 33 & 559 \\
\hline LVdf P1 Bw 1 & 6 & 416 & 359 & 50 & 185 & 34 & 594 \\
\hline LVdf P1 Bw2 & 6 & 412 & 367 & 15 & 175 & 32 & 557 \\
\hline LVdf P1 Bw 1 & 6 & 416 & 359 & 50 & 185 & 34 & 594 \\
\hline LVdf P2 Bw2 & 6 & 414 & 370 & 25 & 243 & 20 & 638 \\
\hline LVdf P3 Bw1 & 6 & 410 & 307 & 68 & 200 & 28 & 575 \\
\hline LVdf P3 Bw2 & 6 & 345 & 342 & 43 & 179 & 37 & 564 \\
\hline
\end{tabular}

(1) Adaptado de Melo et al. (2008), de onde se obtêm os detalhes metodológicos das análises mineralógicas. Classes de agregados $1-2$ a $4 \mathrm{~mm} ; 2-1$ a $2 \mathrm{~mm} ; 3-0,5$ a $1 \mathrm{~mm} ; 4-0,25$ a $0,5 \mathrm{~mm} ; 5-0,105$ a $0,25 \mathrm{~mm}$; e $6-<0,105 \mathrm{~mm}$. Caulinita e gibbsita: determinadas com base na análise termogravimétrica; Hematita e goethita: quantificadas com base no teor de $\mathrm{Fe}_{2} \mathrm{O}_{3}$ obtido na extração com ditionito-citrato-bicarbonato de sódio e características obtidas por difratometria de raios X; Material amorfo: determinado pela redução em massa da amostra pelo tratamento com oxalato de amônio ácido; Óx. total: soma dos óxidos de $\mathrm{Fe}$ e $\mathrm{Al}$ cristalinos (gibbsita + goethita + hematita). 
Quadro 2. Distribuição e diâmetro médio geométrico (DMG) dos agregados dos horizontes Bw1 e Bw2 de diferentes perfis do Latossolo Bruno (LBd) e do Latossolo Vermelho (LVdf)

Amostra Solo Perfil Horizonte 2-4 mm 1-2 mm 0,5-1 mm 0,25-0,5 mm 0,105-0,25 mm $<0,105 \mathrm{~mm}$ DMG

\begin{tabular}{|c|c|c|c|c|c|c|c|c|c|c|}
\hline & & & & & & & $\%$ & 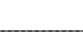 & 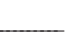 & $\mathrm{mm}$ \\
\hline 1 & $\mathrm{LBd}$ & $\mathrm{P} 1$ & Bw1 & 15,6 & 14,6 & 15,7 & 23,5 & 19,8 & 10,8 & 0,49 \\
\hline 2 & LBd & $\mathrm{P} 1$ & $\mathrm{Bw} 2$ & 16,3 & 16,4 & 16,2 & 22,6 & 18,3 & 10,1 & 0,53 \\
\hline 3 & $\mathrm{LBd}$ & $\mathrm{P} 2$ & Bw1 & 13,5 & 15,4 & 16,6 & 23,6 & 19,5 & 11,3 & 0,47 \\
\hline 4 & $\mathrm{LBd}$ & P2 & $\mathrm{Bw} 2$ & 26,4 & 20,1 & 16,2 & 17,4 & 12,4 & 7,4 & 0,76 \\
\hline 5 & $\mathrm{LBd}$ & P3 & Bw1 & 12,5 & 15,4 & 18,5 & 25,4 & 18,5 & 9,7 & 0,49 \\
\hline 6 & $\mathrm{LBd}$ & P3 & $\mathrm{Bw} 2$ & 32,3 & 18,8 & 14,3 & 15,2 & 11,6 & 7,8 & 0,83 \\
\hline 7 & $\mathrm{LBd}$ & $\mathrm{P} 4$ & Bw 1 & 27,3 & 19,7 & 15,2 & 16,9 & 12,9 & 8,0 & 0,75 \\
\hline 8 & $\mathrm{LBd}$ & $\mathrm{P} 4$ & $\mathrm{Bw} 2$ & 29,6 & 19,1 & 15,5 & 14,5 & 12,1 & 9,2 & 0,77 \\
\hline 9 & LVdf & P 5 & Bw 1 & 12,8 & 14,0 & 15,1 & 23,5 & 21,2 & 13,5 & 0,43 \\
\hline 10 & LVdf & P5 & $\mathrm{Bw} 2$ & 10,5 & 11,7 & 14,7 & 24,7 & 23,2 & 15,2 & 0,38 \\
\hline 11 & LVdf & P6 & Bw 1 & 14,1 & 15,2 & 16,3 & 23,8 & 19,7 & 10,9 & 0,48 \\
\hline 12 & $\mathrm{LVdf}$ & P6 & $\mathrm{Bw} 2$ & 20,3 & 17,4 & 15,7 & 20,7 & 16,4 & 9,5 & 0,60 \\
\hline 13 & LVdf & $\mathrm{P} 7$ & Bw1 & 10,0 & 14,2 & 18,5 & 26,0 & 20,3 & 11,0 & 0,44 \\
\hline 14 & LVdf & P7 & $\mathrm{Bw} 2$ & 6,4 & 11,2 & 16,3 & 27,7 & 24,8 & 13,6 & 0,36 \\
\hline
\end{tabular}

Quadro 3. Análise de correlação entre os teores de minerais na fração argila das diferentes classes de agregados e a percentagem de agregados retidos nas peneiras para o Latossolo Bruno (LBd) e para o Latossolo Vermelho (LVdf) $)^{(1)}$

\begin{tabular}{|c|c|c|c|c|c|c|c|c|}
\hline \multirow{2}{*}{ Agregado } & \multicolumn{4}{|c|}{ LBd } & \multicolumn{4}{|c|}{ LVdf } \\
\hline & Caulinita & Gibbsita & Goethita & Hematita & Caulinita & Gibbsita & Goethita & Hematita \\
\hline $4-2 \mathrm{~mm}$ & $0,9^{* *}$ & $-0,4$ & $-0,5$ & $-0,1$ & $0,8^{\circ}$ & 0,4 & $-0,8^{\circ}$ & 0,5 \\
\hline $2-1 \mathrm{~mm}$ & $0,7^{\circ}$ & $-0,5$ & $-0,6$ & 0,2 & 0,4 & 0,1 & 0,3 & 0,2 \\
\hline $1-0,5 \mathrm{~mm}$ & $-0,8^{*}$ & 0,3 & 0,4 & $-0,2$ & 0,1 & $0,9^{*}$ & 0,1 & $-0,1$ \\
\hline $0,5-0,25 \mathrm{~mm}$ & $-0,6$ & 0,6 & 0,4 & $-0,2$ & $-0,9^{* *}$ & $-0,4$ & 0,4 & $-0,8^{*}$ \\
\hline $0,25-0,105 \mathrm{~mm}$ & $-0,8^{*}$ & 0,6 & 0,5 & 0,1 & $-0,5$ & 0,1 & 0,1 & $-0,7$ \\
\hline$<0,105 \mathrm{~mm}$ & $-0,7^{\circ}$ & $-0,2$ & $0,8^{*}$ & $-0,3$ & $-0,1$ & 0,1 & $-0,2$ & $-0,9^{*}$ \\
\hline
\end{tabular}

discutido para os valores de DMG, esse comportamento é atribuído ao efeito desorganizador dos óxidos de Fe e Al cristalinos no ajuste dos cristais de caulinita, reduzindo o tamanho dos agregados. O efeito oposto desses minerais na classe de $2-4 \mathrm{~mm}$ no LVdf, onde os maiores teores de gibbsita + goethita + hematita favoreceram o aumento da área dos agregados $\left(\mathrm{r}=0,91^{*}\right)$, pode ser relacionado à maior tendência de neutralização das cargas negativas da caulinita, o que contribuiu para o crescimento dos agregados (o efeito de floculação de partículas foi mais importante no crescimento dos agregados que o efeito físico da forma 
Quadro 4. Valores médios de área, perímetro, alongamento, arredondamento, diâmetro de Feret e compacidade de agregados entre 2 e $4 \mathrm{~mm}$ de diâmetro, obtidos dos horizontes Bw1 e Bw2 de diferentes perfis do Latossolo Bruno (LBd) e Latossolo Vermelho (LVdf)

\begin{tabular}{|c|c|c|c|c|}
\hline \multirow{2}{*}{ Perfil } & \multicolumn{2}{|c|}{ LBd } & \multicolumn{2}{|c|}{ LVdf } \\
\hline & Bw 1 & Bw 2 & Bw 1 & Bw2 \\
\hline \multicolumn{5}{|c|}{ Área, $\mathrm{mm}^{2}$} \\
\hline 1 & 9,6 & 10,5 & 7,0 & 7,5 \\
\hline 2 & 9,9 & 10,0 & 8,3 & 7,8 \\
\hline 3 & 10,2 & 11,8 & 6,3 & 7,4 \\
\hline 4 & 10,4 & 10,5 & & \\
\hline \multicolumn{5}{|c|}{$\Sigma$ Área/Massa, $\mathrm{cm}^{2} \mathrm{~g}^{-1(1)}$} \\
\hline 1 & 3,8 & 4,8 & 5,9 & 5,6 \\
\hline 2 & 4,6 & 4,8 & 5,0 & 5,2 \\
\hline 3 & 5,1 & 4,4 & 5,4 & 5,7 \\
\hline 4 & 4,6 & 4,5 & & \\
\hline \multicolumn{5}{|c|}{ Perímetro, mm } \\
\hline 1 & 17,7 & 15,3 & 14,0 & 14,4 \\
\hline 2 & 15,6 & 14,3 & 16,2 & 14,4 \\
\hline 3 & 15,1 & 16,2 & 13,7 & 14,2 \\
\hline 4 & 15,1 & 14,1 & & \\
\hline \multicolumn{5}{|c|}{$\Sigma$ Perímetro/Massa, $\mathrm{cm} \mathrm{g}^{-1(2)}$} \\
\hline 1 & 70,5 & 70,7 & 117,0 & 107,5 \\
\hline 2 & 79,1 & 68,1 & 96,5 & 94,7 \\
\hline 3 & 76,3 & 60,5 & 117,0 & 107,8 \\
\hline 4 & 67,1 & 60,0 & & \\
\hline \multicolumn{5}{|c|}{ Alongamento } \\
\hline 1 & 0,691 & 0,671 & 0,675 & 0,678 \\
\hline 2 & 0,682 & 0,663 & 0,656 & 0,664 \\
\hline 3 & 0,679 & 0,671 & 0,652 & 0,660 \\
\hline 4 & 0,669 & 0,673 & & \\
\hline \multicolumn{5}{|c|}{ Arredondamento } \\
\hline 1 & 0,407 & 0,569 & 0,474 & 0,480 \\
\hline 2 & 0,527 & 0,620 & 0,430 & 0,495 \\
\hline 3 & 0,568 & 0,572 & 0,450 & 0,485 \\
\hline 4 & 0,582 & 0,657 & & \\
\hline \multicolumn{5}{|c|}{ Diâmetro de Feret, mm } \\
\hline 1 & 3,425 & 3,557 & 2,924 & 3,045 \\
\hline 2 & 3,507 & 3,512 & 3,213 & 3,082 \\
\hline 3 & 3,505 & 3,832 & 2,786 & 3,027 \\
\hline 4 & 3,591 & 3,599 & & \\
\hline \multicolumn{5}{|c|}{ Compacidade } \\
\hline 1 & 0,038 & 0,039 & 0,033 & 0,036 \\
\hline 2 & 0,038 & 0,042 & 0,037 & 0,036 \\
\hline 3 & 0,041 & 0,046 & 0,034 & 0,036 \\
\hline 4 & 0,043 & 0,043 & & \\
\hline
\end{tabular}

(1) Área total (AT), sobre massa de agregados (MA) analisados no scanner: [AT (mm²)/MA (g)]/100. ${ }^{(2)}$ Perímetro total (PT), sobre massa de agregados (MA) analisados no scanner: [PT (mm)/MA (g)]/10.

dos minerais), principalmente por se tratar de um solo mais oxídico (Quadro 1). Nos valores de $\mathrm{pH}$ normalmente observados para os solos brasileiros (3,5 a 6,5), a caulinita apresenta predomínio de cargas negativas, e a hematita, predomínio de cargas positivas (Fontes et al., 2001; Denef et al., 2002). Devido à relação entre as variáveis, esse comportamento também foi verificado para o perímetro das classes de agregados do LBd e do LVdf (Quadro 8).

Dentro de uma mesma classe, de maneira geral, os agregados do LBd apresentaram maior área que o 
Quadro 5. Valores médios de área, perímetro, alongamento, arredondamento, diâmetro de Feret e compacidade de agregados entre 1 e 2 mm de diâmetro, obtidos dos horizontes Bw1 e Bw2 de diferentes perfis do Latossolo Bruno (LBd) e Latossolo Vermelho (LVdf)

\begin{tabular}{|c|c|c|c|c|}
\hline \multirow[b]{2}{*}{ Perfil } & \multicolumn{2}{|c|}{ LBd } & \multicolumn{2}{|c|}{ LVdf } \\
\hline & Bw1 & Bw 2 & Bw1 & Bw2 \\
\hline \multicolumn{5}{|c|}{ Área, $\mathrm{mm}^{2}$} \\
\hline 1 & 3,3 & 3,4 & 2,9 & 2,4 \\
\hline 2 & 3,2 & 3,6 & 3,0 & 2,9 \\
\hline 3 & 2,7 & 3,1 & 2,4 & 3,2 \\
\hline 4 & 3,2 & 3,3 & & \\
\hline \multicolumn{5}{|c|}{$\Sigma$ Área/Massa, $\mathrm{cm}^{2} \mathrm{~g}^{-1(1)}$} \\
\hline 1 & 10,0 & 9,9 & 9,9 & 10,6 \\
\hline 2 & 9,8 & 9,8 & 9,2 & 9,0 \\
\hline 3 & 10,7 & 9,5 & 9,1 & 9,1 \\
\hline 4 & 9,4 & 9,5 & & \\
\hline \multicolumn{5}{|c|}{ Perímetro, mm } \\
\hline 1 & 8,0 & 8,0 & 7,7 & 6,9 \\
\hline 2 & 7,7 & 8,1 & 7,9 & 7,8 \\
\hline 3 & 7,1 & 7,5 & 7,1 & 8,4 \\
\hline 4 & 7,5 & 7,5 & & \\
\hline \multicolumn{5}{|c|}{$\Sigma$ Perímetro/Massa, $\mathrm{cm} \mathrm{g}^{-1(2)}$} \\
\hline 1 & 246 & 232 & 269 & 302 \\
\hline 2 & 236 & 219 & 243 & 241 \\
\hline 3 & 275 & 232 & 265 & 237 \\
\hline 4 & 221 & 218 & & \\
\hline \multicolumn{5}{|c|}{ Alongamento } \\
\hline 1 & 0,685 & 0,676 & 0,685 & 0,677 \\
\hline 2 & 0,671 & 0,677 & 0,673 & 0,670 \\
\hline 3 & 0,691 & 0,653 & 0,652 & 0,644 \\
\hline 4 & 0,705 & 0,659 & & \\
\hline \multicolumn{5}{|c|}{ Arredondamento } \\
\hline 1 & 0,643 & 0,659 & 0,614 & 0,651 \\
\hline 2 & 0,673 & 0,695 & 0,612 & 0,613 \\
\hline 3 & 0,689 & 0,683 & 0,623 & 0,594 \\
\hline 4 & 0,705 & 0,723 & & \\
\hline \multicolumn{5}{|c|}{ Diâmetro de Feret, mm } \\
\hline 1 & 1,987 & 2,044 & 1,882 & 1,727 \\
\hline 2 & 1,991 & 2,122 & 1,938 & 1,894 \\
\hline 3 & 1,841 & 1,948 & 1,733 & 1,997 \\
\hline 4 & 1,986 & 2,020 & & \\
\hline \multicolumn{5}{|c|}{ Compacidade } \\
\hline 1 & 0,023 & 0,024 & 0,022 & 0,020 \\
\hline 2 & 0,024 & 0,025 & 0,022 & 0,022 \\
\hline 3 & 0,023 & 0,024 & 0,022 & 0,024 \\
\hline 4 & 0,023 & 0,023 & & \\
\hline
\end{tabular}

(1) Área total (AT), sobre massa de agregados (MA) analisados no scanner: [AT (mm²)/MA (g)]/100. ${ }^{(2)}$ Perímetro total (PT), sobre massa de agregados (MA) analisados no scanner: [PT (mm)/MA (g)]/10.

LVdf (Quadros 4 a 7). Provavelmente o maior teor de caulinita no primeiro solo (Quadro 1) tenha sido decisivo para essa diferença. O maior "perímetro específico" (somatório do perímetro sobre a massa dos agregados) dos horizontes do LVdf também foi consistentemente maior em relação ao LBd nas duas maiores classes, resultado do menor tamanho médio dos agregados.

Olszevski et al. (2004) utilizaram a mesma técnica de estudo dos agregados de um Latossolo Vermelho distrófico submetido a diferentes sistemas de manejo e obtiveram valores médios inferiores para os 
Quadro 6. Valores médios de área, perímetro, alongamento, arredondamento, diâmetro de Feret e compacidade de agregados entre 0,5 e $1 \mathrm{~mm}$ de diâmetro, obtidos dos horizontes Bw1 e Bw2 de diferentes perfis do Latossolo Bruno (LBd) e Latossolo Vermelho (LVdf)

\begin{tabular}{|c|c|c|c|c|}
\hline \multirow{2}{*}{ Perfil } & \multicolumn{2}{|c|}{ LBd } & \multicolumn{2}{|c|}{ LVdf } \\
\hline & Bw 1 & Bw 2 & Bw 1 & Bw 2 \\
\hline \multicolumn{5}{|c|}{ Área, $\mathrm{mm}^{2}$} \\
\hline 1 & 0,723 & 0,713 & 0,666 & 0,611 \\
\hline 2 & 0,657 & 0,688 & 0,788 & 0,740 \\
\hline 3 & 0,850 & 0,864 & 0,703 & 0,583 \\
\hline 4 & 0,875 & 0,692 & & \\
\hline \multicolumn{5}{|c|}{$\Sigma$ Área/Massa, $\mathrm{cm}^{2} \mathrm{~g}^{-1(1)}$} \\
\hline 1 & 22,3 & 23,2 & 20,5 & 22,4 \\
\hline 2 & 22,3 & 25,2 & 18,9 & 19,0 \\
\hline 3 & 20,1 & 22,4 & 17,2 & 19,9 \\
\hline 4 & 20,5 & 22,9 & & \\
\hline \multicolumn{5}{|c|}{ Perímetro, mm } \\
\hline 1 & 3,4 & 3,4 & 3,3 & 3,1 \\
\hline 2 & 3,2 & 3,2 & 3,6 & 3,4 \\
\hline 3 & 3,7 & 3,8 & 3,4 & 3,0 \\
\hline 4 & 3,7 & 3,3 & & \\
\hline \multicolumn{5}{|c|}{$\Sigma$ Perímetro/Massa, $\mathrm{cm} \mathrm{g}^{-1(2)}$} \\
\hline 1 & 1053 & 1092 & 1006 & 1125 \\
\hline 2 & 1091 & 1183 & 864 & 880 \\
\hline 3 & 875 & 984 & 833 & 833 \\
\hline 4 & 878 & 1081 & & \\
\hline \multicolumn{5}{|c|}{ Alongamento } \\
\hline 1 & 0,680 & 0,663 & 0,683 & 0,684 \\
\hline 2 & 0,648 & 0,689 & 0,643 & 0,680 \\
\hline 3 & 0,684 & 0,678 & 0,669 & 0,705 \\
\hline 4 & 0,686 & 0,694 & & \\
\hline \multicolumn{5}{|c|}{ Arredondamento } \\
\hline 1 & 0,783 & 0,789 & 0,777 & 0,804 \\
\hline 2 & 0,790 & 0,811 & 0,756 & 0,778 \\
\hline 3 & 0,772 & 0,758 & 0,759 & 0,797 \\
\hline 4 & 0,779 & 0,811 & & \\
\hline \multicolumn{5}{|c|}{ Diâmetro de Feret, mm } \\
\hline 1 & 0,944 & 0,937 & 0,906 & 0,866 \\
\hline 2 & 0,899 & 0,918 & 0,983 & 0,956 \\
\hline 3 & 1,026 & 1,025 & 0,935 & 0,846 \\
\hline 4 & 1,036 & 0,922 & & \\
\hline \multicolumn{5}{|c|}{ Compacidade } \\
\hline 1 & 0,012 & 0,011 & 0,011 & 0,011 \\
\hline 2 & 0,010 & 0,011 & 0,012 & 0,011 \\
\hline 3 & 0,012 & 0,012 & 0,011 & 0,010 \\
\hline 4 & 0,012 & 0,010 & & \\
\hline
\end{tabular}

(1) Área total (AT), sobre massa de agregados (MA) analisados no scanner: [AT (mm²)/MA (g)]/100. ${ }^{(2)}$ Perímetro total (PT), sobre massa de agregados (MA) analisados no scanner: [PT (mm)/MA (g)]/10.

parâmetros área e perímetro. Uma das explicações para esse comportamento pode ser que os agregados do presente estudo foram coletados em área de preservação ambiental (vegetação nativa), onde a falta de manejo do solo favoreceu a manutenção do tamanho dos agregados.

Estudos morfológicos a campo, de forma generalizada, definem a forma de agregados dos 
Quadro 7. Valores médios de área, perímetro, alongamento, arredondamento, diâmetro de Feret e compacidade de agregados entre 0,25 e $0,5 \mathrm{~mm}$ de diâmetro, obtidos dos horizontes Bw1 e Bw2 de diferentes perfis do Latossolo Bruno (LBd) e Latossolo Vermelho (LVdf)

\begin{tabular}{|c|c|c|c|c|}
\hline \multirow{2}{*}{ Perfil } & \multicolumn{2}{|c|}{ LBd } & \multicolumn{2}{|c|}{ LVdf } \\
\hline & Bw 1 & Bw 2 & Bw 1 & Bw 2 \\
\hline \multicolumn{5}{|c|}{ Área, $\mathrm{mm}^{2}$} \\
\hline 1 & 0,283 & 0,241 & 0,231 & 0,261 \\
\hline 2 & 0,233 & 0,270 & 0,250 & 0,251 \\
\hline 3 & 0,252 & 0,301 & 0,242 & 0,235 \\
\hline 4 & 0,283 & 0,340 & & \\
\hline \multicolumn{5}{|c|}{$\Sigma$ Área/Massa, $\mathrm{cm}^{2} \mathrm{~g}^{-1(1)}$} \\
\hline 1 & 37,8 & 39,3 & 32,7 & 31,3 \\
\hline 2 & 39,5 & 40,1 & 32,0 & 33,0 \\
\hline 3 & 36,8 & 39,2 & 28,2 & 31,1 \\
\hline 4 & 37,8 & 36,8 & & \\
\hline \multicolumn{5}{|c|}{ Perímetro, mm } \\
\hline 1 & 2,1 & 1,9 & 1,8 & 2,0 \\
\hline 2 & 1,8 & 2,0 & 1,9 & 1,9 \\
\hline 3 & 1,9 & 2,1 & 1,9 & 1,8 \\
\hline 4 & 2,0 & 2,2 & & \\
\hline \multicolumn{5}{|c|}{$\Sigma$ Perímetro/Massa, cm g ${ }^{-1(2)}$} \\
\hline 1 & 2750 & 3069 & 2585 & 2338 \\
\hline 2 & 3114 & 2937 & 2490 & 2514 \\
\hline 3 & 2800 & 2781 & 2225 & 2437 \\
\hline 4 & 2701 & 2432 & & \\
\hline \multicolumn{5}{|c|}{ Alongamento } \\
\hline 1 & 0,708 & 0,660 & 0,689 & 0,663 \\
\hline 2 & 0,674 & 0,691 & 0,700 & 0,680 \\
\hline 3 & 0,687 & 0,683 & 0,656 & 0,684 \\
\hline 4 & 0,674 & 0,656 & & \\
\hline \multicolumn{5}{|c|}{ Arredondamento } \\
\hline 1 & 0,846 & 0,862 & 0,867 & 0,861 \\
\hline 2 & 0,870 & 0,865 & 0,855 & 0,864 \\
\hline 3 & 0,859 & 0,836 & 0,838 & 0,867 \\
\hline 4 & 0,865 & 0,845 & & \\
\hline \multicolumn{5}{|c|}{ Diâmetro de Feret, mm } \\
\hline 1 & 0,590 & 0,545 & 0,537 & 0,571 \\
\hline 2 & 0,540 & 0,579 & 0,558 & 0,560 \\
\hline 3 & 0,560 & 0,608 & 0,550 & 0,542 \\
\hline 4 & 0,594 & 0,649 & & \\
\hline \multicolumn{5}{|c|}{ Compacidade } \\
\hline 1 & 0,007 & 0,006 & 0,006 & 0,007 \\
\hline 2 & 0,006 & 0,007 & 0,006 & 0,007 \\
\hline 3 & 0,006 & 0,007 & 0,007 & 0,006 \\
\hline 4 & 0,007 & 0,008 & & \\
\hline
\end{tabular}

(1) Área total (AT), sobre massa de agregados (MA) analisados no scanner: [AT (mm²)/MA (g)]/100. ${ }^{(2)}$ Perímetro total (PT), sobre massa de agregados (MA) analisados no scanner: [PT (mm)/MA (g)]/10.

Latossolos como sendo esferoidal, o que não é comprovado pelos dados do presente estudo (Figuras $1 b$ e 2b). Os valores do parâmetro alongamento, para todas as classes de agregados (Quadros 4 a 7), ficaram abaixo de 1,0, indicando a forma mais poliedral das estruturas. Verifica-se tendência de os agregados do horizonte $\mathrm{Bw} 2$ do $\mathrm{LBd}$ apresentarem menores valores de alongamento que o Bw1 (Quadros 4 a 7), ou seja, estruturas com maior diferença entre o maior e o menor eixo (valores de alongamento mais próximos a 
Quadro 8. Análise de correlação entre os teores dos minerais obtidos em cada classe de agregado com os atributos morfológicos médios, também das diferentes classes de agregados do Latossolo Bruno (LBd) e do Latossolo Vermelho (LVdf)

\begin{tabular}{|c|c|c|c|c|c|c|c|c|c|c|c|c|}
\hline \multirow{2}{*}{ Classe } & \multicolumn{6}{|c|}{ LBd } & \multicolumn{6}{|c|}{ LVdf } \\
\hline & $\mathrm{Ct}$ & Gb & Gt & $\mathrm{Hm}$ & Am & Óx. total & $\mathrm{Ct}$ & Gb & Gt & $\mathrm{Hm}$ & Am & Óx. total \\
\hline & \multicolumn{12}{|c|}{ Área } \\
\hline $2-4 \mathrm{~mm}$ & 0,30 & $-0,11$ & $-0,53$ & 0,25 & 0,16 & $-0,13$ & 0,11 & $0,92^{* *}$ & $-0,82^{*}$ & 0,66 & $-0,54$ & $0,91^{*}$ \\
\hline $1-2 \mathrm{~mm}$ & 0,50 & $-0,41$ & $-0,51$ & 0,29 & $-0,35$ & $-0,41$ & $-0,39$ & 0,40 & 0,43 & 0,02 & $-0,16$ & 0,61 \\
\hline $0,5-1 \mathrm{~mm}$ & 0,05 & 0,32 & $-0,39$ & 0,31 & 0,45 & 0,19 & 0,35 & 0,10 & $-0,28$ & 0,42 & $-0,68$ & 0,30 \\
\hline \multirow{2}{*}{$0,25-0,5 \mathrm{~mm}$} & 0,31 & $-0,74^{\circ}$ & 0,14 & $-0,30$ & $-0,30$ & $-0,87^{* *}$ & 0,51 & 0,36 & $-0,67$ & 0,13 & $-0,44$ & 0,08 \\
\hline & \multicolumn{12}{|c|}{ Perímetro } \\
\hline $2-4 \mathrm{~mm}$ & $-0,56$ & 0,56 & 0,21 & 0,40 & 0,60 & $0,63^{\circ}$ & 0,24 & 0,70 & $-0,52$ & $0,77^{\circ}$ & $-0,77^{\circ}$ & $0,91^{*}$ \\
\hline $1-2 \mathrm{~mm}$ & 0,12 & 0,08 & $-0,45$ & 0,45 & $-0,37$ & 0,06 & $-0,47$ & 0,27 & 0,50 & 0,06 & $-0,23$ & 0,50 \\
\hline $0,5-1 \mathrm{~mm}$ & 0,03 & 0,32 & $-0,40$ & 0,39 & 0,39 & 0,21 & 0,35 & 0,01 & $-0,20$ & 0,26 & $-0,59$ & 0,15 \\
\hline \multirow[t]{2}{*}{$0,25-0,5 \mathrm{~mm}$} & 0,22 & $-0,65^{\circ}$ & 0,13 & $-0,25$ & $-0,34$ & $-0,77^{*}$ & 0,44 & 0,14 & $-0,53$ & 0,12 & $-0,35$ & 0,04 \\
\hline & \multicolumn{12}{|c|}{ Alongamento } \\
\hline $2-4 \mathrm{~mm}$ & $-0,67^{\circ}$ & 0,42 & $0,68^{\circ}$ & 0,01 & 0,37 & 0,50 & 0,10 & 0,45 & $-0,41$ & $-0,56$ & 0,64 & $-0,20$ \\
\hline $1-2 \mathrm{~mm}$ & $-0,30$ & 0,48 & 0,22 & 0,10 & 0,34 & 0,42 & 0,55 & 0,54 & $-0,32$ & 0,46 & 0,39 & 0,49 \\
\hline $0,5-1 \mathrm{~mm}$ & 0,13 & $-0,53$ & $-0,59$ & $-0,11$ & 0,45 & $-0,64^{\circ}$ & $-0,28$ & 0,03 & 0,46 & 0,02 & 0,68 & 0,10 \\
\hline \multirow[t]{2}{*}{$0,25-0,5 \mathrm{~mm}$} & $-0,78^{*}$ & 0,46 & 0,05 & 0,09 & 0,01 & 0,38 & 0,17 & 0,50 & $-0,18$ & 0,03 & 0,11 & 0,32 \\
\hline & \multicolumn{12}{|c|}{ Arredondamento } \\
\hline $2-4 \mathrm{~mm}$ & $0,70^{\circ}$ & $-0,64^{\circ}$ & $-0,37$ & $-0,35$ & $-0,53$ & $-0,71^{*}$ & $-0,31$ & 0,11 & $-0,28$ & $-0,46$ & 0,62 & $-0,33$ \\
\hline $1-2 \mathrm{~mm}$ & 0,56 & $-0,57$ & 0,02 & $-0,42$ & 0,08 & $-0,60$ & 0,62 & 0,08 & $-0,77^{\circ}$ & 0,33 & 0,30 & $-0,22$ \\
\hline $0,5-1 \mathrm{~mm}$ & 0,12 & $-0,64^{\circ}$ & 0,07 & $-0,48$ & 0,08 & $-0,60$ & $-0,21$ & 0,40 & 0,02 & 0,02 & 0,41 & 0,12 \\
\hline \multirow[t]{2}{*}{$0,25-0,5 \mathrm{~mm}$} & 0,06 & 0,33 & $-0,16$ & 0,35 & 0,32 & 0,34 & 0,06 & $0,84^{*}$ & $-0,59$ & 0,33 & 0,34 & 0,68 \\
\hline & \multicolumn{12}{|c|}{ Diâmetro de Feret } \\
\hline $2-4 \mathrm{~mm}$ & 0,36 & $-0,20$ & $-0,50$ & $-0,35$ & $-0,54$ & $-0,71^{*}$ & 0,16 & $0,87^{\circ}$ & $-0,79^{\circ}$ & $0,75^{\circ}$ & $-0,60$ & $0,94^{* *}$ \\
\hline $1-2 \mathrm{~mm}$ & 0,52 & $-0,33$ & $-0,32$ & 0,09 & $-0,27$ & $-0,35$ & $-0,36$ & 0,37 & 0,46 & 0,06 & $-0,12$ & $-0,22$ \\
\hline $0,5-1 \mathrm{~mm}$ & 0,02 & 0,33 & $-0,38$ & 0,30 & 0,49 & 0,20 & 0,39 & 0,07 & $-0,23$ & 0,42 & $-0,66$ & 0,30 \\
\hline \multirow[t]{2}{*}{$0,25-0,5 \mathrm{~mm}$} & 0,30 & $-0,73^{*}$ & $-0,17$ & $-0,25$ & $-0,28$ & $-0,87^{* *}$ & 0,50 & 0,35 & $-0,66$ & 0,13 & $-0,45$ & 0,08 \\
\hline & \multicolumn{12}{|c|}{ Compacidade } \\
\hline $2-4 \mathrm{~mm}$ & $0,74^{*}$ & $-0,14$ & $-0,50$ & 0,03 & 0,02 & $-0,24$ & 0,01 & 0,65 & $-0,51$ & $0,76^{\circ}$ & $-0,75^{\circ}$ & $0,88^{*}$ \\
\hline $1-2 \mathrm{~mm}$ & 0,31 & 0,04 & $-0,43$ & 0,61 & $-0,81^{*}$ & 0,10 & $-0,72$ & $-0,24$ & $-0,25$ & $0,74^{\circ}$ & $-0,43$ & $-0,23$ \\
\hline $0,5-1 \mathrm{~mm}$ & 0,18 & 0,54 & $-0,40$ & 0,60 & 0,29 & 0,44 & 0,33 & 0,27 & $-0,47$ & 0,08 & $-0,60$ & 0,03 \\
\hline $0,25-0,5 \mathrm{~mm}$ & 0,30 & $-0,77^{*}$ & $-0,19$ & 0,23 & $-0,40$ & $-0,90^{* *}$ & 0,34 & $-0,18$ & 0,10 & 0,36 & $-0,57$ & 0,05 \\
\hline
\end{tabular}

(1) Ct: caulinita, Gb: gibbsita, Gt: goethita, Hm: hematita, Am: quantidade de mineral de baixa cristalinidade extraída pelo oxalato de amônio, Ox. total: total dos óxidos cristalinos $(\mathrm{Gb}+\mathrm{Gt}+\mathrm{Hm})$ (Melo et al., 2008). ${ }^{\circ},{ }^{*},{ }^{* *}$ coeficientes de correlação (r) significativos a 0,$1 ; 0,05$; e 0,01 , respectivamente, pelo teste t. Para o LBd foram analisadas oito observações (quatro perfis x dois horizontes) e para o LVdf apenas seis (três perfis x dois horizontes).

1,0 indicam agregados mais esféricos). Para as classes de 2-4 e 0,25-0,5 mm, o maior teor de caulinita nos horizontes do LBd contribuiu para melhor ajuste dos cristais desse mineral, induzindo ao crescimento da estrutura preferencialmente em uma direção (correlações negativas e significativas entre teor de caulinita e alongamento para essas classes Quadro 8).
Os agregados apresentaram rugosidade (valores de arredondamento menores que 1 - Quadros 4 a 7), o que contribui para aumentar sua superfície externa. O grau de arredondamento aumentou significativamente com a diminuição da classe dos agregados para ambos os solos e horizontes, ou seja, agregados menores tendem a ser mais esféricos e arredondados. Especificamente para a classe de 2-4 $\mathrm{mm}$ dos horizontes do 
LBd, além do aparente efeito da caulinita em tornar os agregados mais poliedrais, os horizontes com maior teor do mineral na fração argila apresentaram maior grau de arredondamento, ou seja, menor rugosidade da superfície ( $r=0,70^{\circ}$ - Quadro 8). Por outro lado, obteve-se correlação negativa entre os teores de óxidos de $\mathrm{Fe}$ e $\mathrm{Al}$ cristalinos e o grau de arredondamento para a classe de agregados de $2-4 \mathrm{~mm}$ do LBd (Quadro 8). Provavelmente, o formato mais isodimensional da hematita, goethita e gibbsita (Schwertmann \& Kämpf, 1985; Melo et al., 2001b) favoreceu o incremento da rugosidade dessa classe de agregados.

Devido à alta interdependência do diâmetro de Feret (DF) com a área dos agregados (r entre DF e área e perímetro $=0,98^{* * *}$ e $0,99^{* * *}$, respectivamente), observou-se o mesmo comportamento para as características dos agregados (Quadros 4 a 7) e suas correlações com os teores dos minerais (Quadro 8), em relação às variáveis área e perímetro.

$\mathrm{O}$ efeito mais expressivo dos óxidos de $\mathrm{Fe}$ e $\mathrm{Al}$ de baixa cristalinidade foi reduzir a compacidade dos agregados da classe de 1- $2 \mathrm{~mm}$ dos horizontes do LBd $\left(\mathrm{r}=-0,81^{*}\right.$ - Quadro 8), em que o valor máximo de 1,0 significa que o agregado é perfeitamente circular. $\mathrm{O}$ baixo efeito dos minerais de menor cristalinidade na morfologia dos agregados pode ser atribuído aos seus reduzidos teores na fração argila dos agregados (Quadro 1). Esse mesmo efeito foi observado na classe de agregados de $0,25-0,5 \mathrm{~mm}$ dos horizontes do $\mathrm{LBd}$ para os óxidos cristalinos (gibbsita + goethita + hematita). Comportamento oposto foi verificado para a caulinita para a classe de $2-4 \mathrm{~mm}$, em que o maior teor do mineral na fração argila dos horizontes do LBd tornou os agregados mais circulares.

Para um determinado atributo morfológico (área, perímetro, arredondamento, diâmetro de Feret e compacidade), o efeito dos teores dos minerais da fração argila para apenas algumas classes de agregados (Quadro 8) pode ser atribuído à influência de outros fatores importantes na formação e definição dos agregados do solo: fatores ambientais, manejo do solo, influência da planta e propriedades do solo, como textura, composição mineral, teor de carbono orgânico, processos pedogenéticos, atividade microbiana, íons trocáveis e umidade (Singer et al., 1992; Denef et al., 2002; Six et al., 2004).

\section{CONCLUSÕES}

1. Os agregados dos Latossolos Bruno (LBd) e Vermelho (LVdf) são predominantemente poliedrais e rugosos, o que deve contribuir para aumentar sua superfície externa. Os maiores valores de diâmetro médio geométrico (DMG), área e perímetro dos agregados foram verificados para o LBd, principalmente para o horizonte mais profundo (Bw2). O grau de arredondamento aumentou com a diminuição da classe de tamanho dos agregados em ambos os solos, ou seja, agregados menores tendem a ser mais esféricos e menos rugosos.

2. A qualidade da fração argila teve efeito não apenas no tamanho dos agregados, mas também na morfologia externa destes. Para algumas classes de tamanho de agregados dos horizontes do LBd e do LVdf, o aumento no DMG e na área, o crescimento preferencial em um eixo (alongamento) e a redução da rugosidade externa dos agregados foram favorecidos pelo maior teor de caulinita na fração argila. Efeito oposto foi observado para os óxidos de $\mathrm{Fe}$ e Al.

\section{AGRADECIMENTOS}

Os autores agradecem ao Professor Elpídio Inácio Fernandes Filho, do Departamento de Solos da Universidade Federal de Viçosa, o apoio na utilização do programa de processamento das imagens.

\section{LITERATURA CITADA}

DENEF, K.; SIX, J.; MERCKX, R. \& PAUSTIAN, K. Shortterm effects of biological and physical forces on aggregates formation in soil with different clay mineralogy. Plant Soil, 246:185-200, 2002.

EDWARDS, A.P. \& BREMMER, J.M. Microaggregates in soils. J. Soil Sci., 18:64-73, 1967.

EMPRESA BRASILEIRA DE PESQUISA AGROPECUÁRIA EMBRAPA. Centro Nacional de Pesquisas de Solos. Sistema brasileiro de classificação de solos. Brasília, Serviço de Produção de Informação, 1999. 412p.

EMPRESA NACIONAL DE PESQUISA AGROPECUÁRIA EMBRAPA. Manual de métodos de análise de solo. 2.ed. Rio de Janeiro, Centro Nacional de Pesquisa de Solos, 1997. 212p.

FERREIRA, M.M.; FERNANDES, B. \& CURI, N. Mineralogia da fração argila e estrutura de Latossolos da Região Sudeste do Brasil. R. Bras. Ci. Solo, 23:507-514, 1999a.

FERREIRA, M.M.; FERNANDES, B. \& CURI, N. Influência da mineralogia da fração argila nas propriedades físicas de Latossolos da Região Sudeste do Brasil. R. Bras. Ci. Solo, 23:515-524, 1999b

FONTES, M.P.F.; CAMARGO, O.A. \& SPOSITO, G. Eletroquímica das partículas coloidais e sua relação com a mineralogia de solos altamente intemperizados. Sci. Agríc., 18:265-271, 2001.

GHIDIN, A.A.; MELO, V.F.; LIMA, V.C. \& LIMA, J.M.J.C. Toposseqüências de Latossolos originados de rochas basálticas no Paraná. I - Mineralogia da fração argila. R. Bras. Ci. Solo, 30:293-306, 2006a.

GHIDIN, A.A.; MELO, V.F.; LIMA, V.C. \& LIMA, J.M.J.C. Toposseqüências de Latossolos originados de rochas basálticas no Paraná. II - Relação entre mineralogia da fração argila e propriedades físicas dos solos. R. Bras. Ci. Solo, 30:307-319, 2006b. 
INSTITUTO AGRONÔMICO DO PARANÁ - IAPAR. Cartas climáticas do Paraná. Londrina, 2000. v.1.0. CD ROOM.

KÄMPF, N.; KLANT, E. \& SCHNEIDER, P. Óxidos de ferro em Latossolos do Brasil Sudeste e Sul. In: REUNIÃO DE CLASSIFICAÇÃO, CORRELAÇÃO DE SOLOS E INTERPRETAÇÃO DE APTIDÃO AGRÍCOLA, 3., Rio de Janeiro, 1988. Anais. Rio de Janeiro, Empresa Brasileira de Pesquisa Agropecuária, Serviço Nacional de Levantamento e Classificação do Solo, 1988a. p.153-183.

KÄMPF, N.; RESENDE, M. \& CURI, N. Iron oxides in Brazilian soils. In: INTERNATIONAL SOIL CLASSIFICATION WORKSHOP, 8., Curitiba, 1988 Anais. Curitiba, Empresa Brasileira de Pesquisa Agropecuária, Universidade Federal do Paraná, 1988b. p.71-77.

KEMPER, W.D. \& ROSENAU, R.C. Aggregate stability and size distribution. In: KLUTE, A., ed. Methods of soil analysis. Parte 1: Physical and mineralogical methods. Madison, American Society of Agronomy, 1986. p.425443 .

MELO, V.F.; SINGH, B.; SCHAEFER, C.E.G.R.; NOVAIS, R.F. \& FONTES, M.P.F. Chemical and mineralogical properties of kaolinite-rich Brazilian soils. Soil Sci. Soc. Am. J, 65:1324-1333, 2001a.

MELO, V.F.; FONTES, M.P.F.; NOVAIS, R.F.; SINGH, B. \& SCHAEFER, C.E.G.R. Características dos óxidos de ferro e de alumínio de diferentes classes de solos. R. Bras. Ci. Solo, 25:19-32, 2001b.

MELO, V.F.; TOLEDO, F.H.; MOURA, R.; LIMA, V.C. \& GHIDIN, A.A. Caracterização química e mineralógica de agregados de diferentes classes de tamanho de Latossolos Brunos e Vermelhos localizados no Estado do Paraná. R. Bras. Ci. Solo, 32:67-83, 2008.

OLSZEVSKI, N.; COSTA L.M.; FERNANDES FILHO, E.I.; RUIZ, H.A.; ALVARENGA, R.C. \& CRUZ, J.C. Morfologia de agregados do solo avaliada por meio de análise de imagens. R. Bras. Ci. Solo, 28:901-909, 2004.
PINHEIRO-DICK, D. \& SCHWERTMANN, U. Características químicas, mineralógicas e morfológicas de microagregados de Oxissolos. In: CONGRESSO BRASILEIRO DE CIÊNCIA DO SOLO, 25., Viçosa, 1995. Resumos expandidos. Viçosa, MG, Sociedade Brasileira de Ciência do Solo, 1995. p.262-264.

RESENDE, M. Aplicações de conhecimentos pedológicos à conservação de solos. Inf. Agropec., 11:3-18, 1985.

RESENDE, M.; CARVALHO FILHO, A. \& LANI, J.L. Características do solo e da paisagem que influenciam a suscetibilidade à erosão. In: SIMPÓSIO SOBRE MANEJO E CONSERVAÇÃO DO SOLO NO CERRADO, Goiânia, 1990, Campinas. Anais. Campinas, Fundação Cargill, 1992. p.32-67.

RESENDE, M.; CURI, N.; REZENDE, S.B. \& CORRÊA, G.F. Pedologia: Base para distinção de ambientes. Viçosa, MG, NEPUT, 1997. 367p.

SCHNEIDER, A.W. Vulcanismo basáltico da bacia do Paraná: Perfil Foz do Iguaçu - Serra da Esperança. In: CONGRESSO BRASILEIRO DE GEOLOGIA, 26. Brasília, 1970. Anais. Brasília, Sociedade Brasileira de Geologia, 1970. p.211-217.

SCHWERMANN, U. \& KAMPF, N. Properties of goethite and hematite in kaolinitic soils of Southern and Central Brazil. J. Soil Sci., 139:344-350, 1985.

SINGER, M.J.; SOUTHARD, R.J.; WARRINGTON, D.J. \& JANITZKY, P. Stability of synthetic sand clay aggregates after wetting and drying cycles. Soil Sci. Soc. Am. J., 56:1843-1848, 1992.

SINGH, B. \& GILKES, R.J. Properties of soil kaolinites from South-Western Australia. J. Soil Sci., 43:645-667, 1992.

SIX, J.; BOSSUYT, H.; DEGRYSE, S. \& DENEF, K. A history of research on the link between (micro)aggregates, soil biota, and organic matter dynamics. Soil Till. Res., 79:731, 2004.

WILCOX, C.D.; DOVE, S.B.; MCDAVID, W.D. \& GREER, D.B. UTHSCSA image tool: Help on-line. San Antonio, Universidade de San Antonio, 1997. Não Paginado. 